\title{
Overexpression of ATP5b promotes cell proliferation in asthma
}

\author{
JIANHONG ZUO ${ }^{1,2^{*}}$, MINGSHENG LEI $^{3 *}$, MEILIN WEN $^{4}$, YIKUN CHEN $^{2}$ and ZHIGANG LIU ${ }^{2}$ \\ ${ }^{1}$ Hunan Province Key Laboratory of Tumor Cellular and Molecular Pathology, Cancer Institute, School \\ of Medicine, University of South China, Hengyang, Hunan 421001; ${ }^{2}$ State Key Laboratory of Respiratory \\ Disease for Allergy, School of Medicine, Shenzhen University, Shenzhen, Guangdong 518060; ${ }^{3}$ Department of \\ Respiratory and Critical Care Medicine, Zhangjiajie City Hospital, Zhangjiajie, Hunan 427000; ${ }^{4}$ Department \\ of Oncology, Nanhua Hospital, University of South China, Hengyang, Hunan 421001, P.R. China
}

Received November 27, 2015; Accepted November 18, 2016

DOI: $10.3892 / \mathrm{mmr} .2017 .7413$

\begin{abstract}
Asthma is a complicated systemic disease of the airways, which is characterized by variable symptoms, including bronchial hyper-responsiveness, inflammation and airflow obstruction. The prevalence of asthma has increased 2-3-fold over recent decades in developed countries; however, the molecular mechanism of asthma remains unclear. In the current study, the expression of recombinant protein Dermatophagoides farinaeI (Derf I) was induced by isopropyl $\beta$-D-1-thiogalactoside (IPTG) and purified using Ni-NTA. Derf I, an important antigen of asthma, was used to establish the animal model of asthma. Airway hyper-responsiveness was measured using unrestrained whole-body plethysmography with a four-chamber system. Immunoglobulin (Ig)E, IgG and $\mathrm{IgG} 2 \mathrm{a}$ were analyzed using indirect enzyme-linked immunosorbent assay (ELISA). Proteomic technology was applied to detect the difference between the normal lung tissue and asthma lung tissue samples of the asthma model. Cytokines in bronchoalveolar lavage fluid and the splenocyte culture medium were measured by ELISA and reverse transcription-quantitative polymerase chain reaction (RT-qPCR) was performed to detect the mRNA expression of ATP synthase, $\mathrm{H}+$ transporting, mitochondrial F1 complex, $\beta$ polypeptide (ATP5b). In addition, cell growth of arterial smooth muscle cells (ASMCs) was evaluated by MTT assay. In the current study, Derf I was successfully used to construct the animal model of asthma. Out of 23 proteins that exhibit 3 -fold upregulation or downregulation, ATP5b was chosen for further investigation. The data indicated that ATP5b was
\end{abstract}

Correspondence to: Professor Zhigang Liu, State Key Laboratory of Respiratory Disease for Allergy, School of Medicine, Shenzhen University, Shenzhen, Guangdong 518060, P.R. China

E-mail:1zg@szu.edu.cn

*Contributed equally

Key words: ATP5b, cell proliferation, proteomics, airway smooth muscle cells, asthma overexpressed in the asthma lung tissue when compared with the normal lung tissue. However, when ATP5b was knocked down, cell growth decreased. Therefore, overexpressed ATP5b leads to airway smooth muscle cell (ASMC) proliferation and finally to ASM thickening. Thus, to the best of our knowledge, this is the first study to report that the expression level of ATP5b was markedly increased in lung tissue samples of an asthma model compared with the tissue samples from normal lungs, which promoted ASMC proliferation and contributed to airway remodeling.

\section{Introduction}

Asthma is a complicated systemic disease of the airways, which is characterized by variable and recurring symptoms, including bronchial hyper-responsiveness, inflammation and airflow obstruction. When an asthma exacerbation occurs, certain symptoms, such as shortness of breath, wheezing, coughing, and chest tightness are uncontrolled (1). Together, the symptoms eventually impair lung function by decreasing the flow of gases to and from the alveoli in the distal lung (2). The prevalence of asthma has increased 2-3-fold over recent decades in developed countries (3-5). It is estimated that asthma affects $\sim 300$ million people in the world and causes a quarter of a million mortalities (6). Globally, asthma accounts for approximately one in every 250 mortalities (7), which is a significant cause of morbidity and mortality in developed countries (8). In America, 9-20\% of children and 1-3\% of adults suffer from asthma $(8,9)$, and the financial burden of asthma is estimated to be $>\$ 10$ billion (10). Furthermore, there is a high prevalence of $\sim 5 \%$ in China (11). Numerous factors, including improved epidemiological reporting, medical care and increased environmental allergens contribute to the increased prevalence. However, the molecular mechanism of asthma remains poorly understood.

Asthma is a chronic airway inflammatory disease, where persistent inflammation in the airway results in structural changes termed airway remodeling (12). Airway smooth muscle cells (ASMCs) confer an abnormally exaggerated bronchoconstriction in asthma, and the phenomenon is commonly referred to as airway hyper-responsiveness (AHR), which is a hallmark characteristic of asthma (13). Airway remodeling encompasses subepithelial fibrosis, deposition of extracellular 
matrix (ECM) proteins, increased smooth muscle mass and mucus gland hyperplasia. Generation of growth factors from patients with asthma drive mesenchymal cell proliferation and differentiation toward increased matrix deposition and smooth muscle production (14-16). Airway remodeling is particularly observed in patients with refractory asthma and progressive decline in lung function (17).

Studies demonstrate that airway remodeling is closely connected with the progression of AHR (18).

It has previously been demonstrated that asthma markedly increases Th2-mediated responses and decreases Th1-mediated responses (19-21). Clinically, the majority of asthma patients show a significant increase in ASM bundles, primarily due to increases in cell number, collectively contributing to airway remodeling (12). Furthermore, airway remodeling is progressive and the degree of structural changes correlates with disease severity (18). In this sense, ASMC hyperplasia has been postulated as the predominant mechanism of ASM thickening (22). Simultaneously, increased proliferation results in decreased pulmonary function in asthmatic patients (23). It is critical to further understand the mechanism of airway remodeling in patients with asthma; however, the molecular mechanisms remain unclear. Thus novel targets must be identified to prevent airway remodeling and thus, treat asthma (24).

In the current study, proteomic technology was applied to analyze the difference between normal lung and asthmatic lung tissue samples. In addition, the molecular mechanisms of asthma were detected.

\section{Materials and methods}

Animals and materials. A total of 20 female BALB/c mice (specific pathogen-free; aged 5-6 weeks; weight, 16-20 g) were purchased from the Animal Center of Guangdong Province (Guangzhou, China) and fed in a specific pathogen-free grade breeding room (separated into two groups of ten, bred separately and conventionally in cages, at a temperature of $18-22^{\circ} \mathrm{C}, 50-60 \%$ humidity and 10-14 h lighting with an air flow of $10-25 \mathrm{~cm} / \mathrm{min})$.

The present study was performed in strict accordance with the recommendations of the Guide for the Care and Use of Laboratory Animals of the National Institutes of Health. The protocol was approved by the Committee on the Ethics of Animal Experiments of Shenzhen University (Shenzhen, China). Reagents and chemicals were analytical grade (Sigma-Aldrich, St. Louis, MO, USA) and solvents were HPLC grade (Mallinckrodt Australia Pty Ltd., NSW, Australia). Sodium dodecyl sulphate-polyacrylamide gel electrophoresis (SDS-PAGE) and western blotting were performed using a Mini Protean II apparatus (Bio-Rad Laboratories, Inc., Hercules, California, USA) with $12 \%$ gels and a Tris/Tricine buffer system. Two-dimensional PAGE was performed using Immobiline IPG strips $(13 \mathrm{~cm})$ with a $\mathrm{pH}$ range of 3-10 (GE Healthcare Life Sciences, Shanghai, China). $\mathrm{Al}(\mathrm{OH})_{3}$ and methacholine were purchased from Sigma-Aldrich. Biotin-labeled goat anti-mouse immunoglobulin $\operatorname{IgE}$ was purchased from Novus Biologicals, (Colorado, USA), horseradish peroxidase (HRP)-labeled goat anti-mouse $\operatorname{IgG}$ and $\operatorname{IgG} 2$ a were obtained from
eBioscience, Inc. (San Diego, CA, USA). Mouse interleukin [IL; IL-4 (catalog no. 431104) and IL-10 (catalog no. 431414)], and interferon (INF) $-\gamma$ enzyme-linked immunosorbent assay (ELISA) kits (catalog no. 430801) were obtained from BioLegend, Inc. (San Diego, CA, USA). The vector of pET-28b/Dermatophagoides farinaeI (Derf I) was constructed in the State Key Laboratory of Respiratory Disease for Allergy, Shenzhen University (Shenzhen, China).

Expression and purification of recombinant protein Derf I. Expression of recombinant protein, Derf I was induced using $1 \mathrm{mM}$ isopropyl $\beta$-D-1-thiogalactopyranoside at mid-log phase at $37^{\circ} \mathrm{C}$ and the samples were collected $4 \mathrm{~h}$ post-induction. Harvested induced cells were lysed with $10 \mathrm{mg} / \mathrm{ml}$ lysozyme in Tris buffer $\left(100 \mathrm{mM} \mathrm{NaH} \mathrm{PO}_{4}\right.$ and $10 \mathrm{mM}$ Tris- $\mathrm{Cl}$ ) and homogenized by sonication. Inclusion bodies were collected by centrifugation at $12,000 \mathrm{x} \mathrm{g}$ for 20 min at $4^{\circ} \mathrm{C}$ and then washed three times with Tris buffer containing $0.5 \%(\mathrm{v} / \mathrm{v})$ Triton $\mathrm{X}-100$. Inclusion bodies, solubilized in $6 \mathrm{M} \mathrm{GuHCl}$, were purified by Ni-NTA at $4^{\circ} \mathrm{C}$. The recombinant protein was electrophoresed $(110 \mathrm{~V})$ on $12 \%(\mathrm{w} / \mathrm{v})$ SDS polyacrylamide gels and its protein concentration was determined using the bicinchoninic acid assay (AppliChem GmbH, Darmstadt, Germany) according to the manufacturer's protocol.

Sensitization and asthma challenge. The animal sensitization model was designed for the following experiment. Briefly, the mice were randomly divided into two groups (20 mice per group). The model groups were sensitized intraperitoneally (I.P.) with $50 \mu \mathrm{g}$ Derf I with $4 \mathrm{mg} \mathrm{Al}(\mathrm{OH})_{3}$ on days 1,3 and 7, while the normal group was sensitized, challenged and treated with phosphate-buffered saline (PBS) and $4 \mathrm{mg} \mathrm{Al}(\mathrm{OH})_{3}$. The model groups were induced with $50 \mu \mathrm{g} / \mathrm{ml}$ Derf I every day for one week, which was substituted with $50 \mu \mathrm{g} / \mathrm{ml}$ PBS in the normal group.

Assessment of AHR to methacholine challenge. Twenty-four $\mathrm{h}$ after the final challenge, AHR was measured using unrestrained whole-body plethysmography with a four-chamber system (Buxco Research Systems, Wilmington, NC, USA) as previously described (25).

PAGE and mass analysis. The recombinant protein Derf I was diluted with an identical volume of lysis buffer $(0.5 \mathrm{~L})$ as follows: 9 mol/1 Urea, $0.8 \%$ IPG buffer ( $\mathrm{pH}, 3-10), 1 \%$ dithiothreitol (DTT) and 2\% 3-[(3-cholamidopropyl) dimethylammonio] propane-1-sulphonic acid. Subsequently, PAGE and mass analysis were performed as described by Cheng et al (26) and Li et al (27).

Determination of allergen-specific IgE, IgGand IgG2a antibodies in serum. Blood samples $(1 \mathrm{ml})$ were obtained from the eyes of the mice, and centrifuged at $4^{\circ} \mathrm{C}$ and $324 \mathrm{x}$ g for $10 \mathrm{~min}$. The supernatant serum was collected and the $\mathrm{IgE}$, IgG, and IgG2a were subsequently analyzed using an indirect ELISA protocol according to the manufacturer's protocol.

Bronchoalveolar lavage fluid (BALF) and differential cell counts. BALF was collected as previously described (28) with 
A

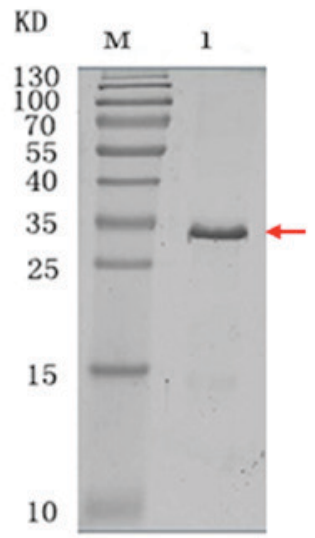

B

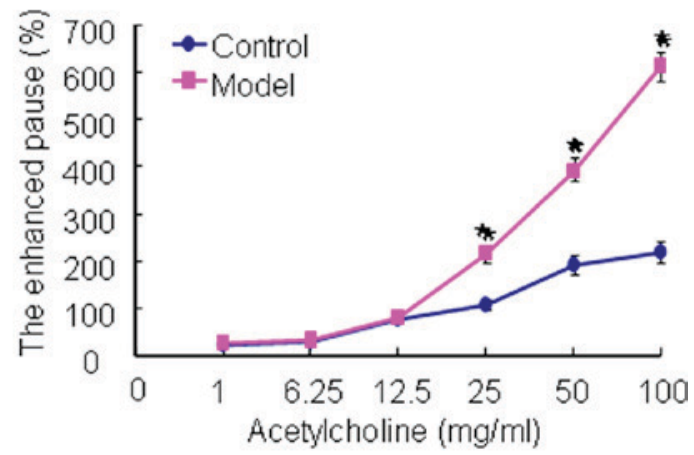

C

a

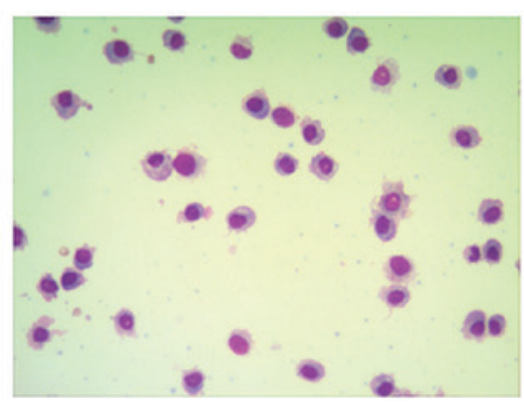

D

a

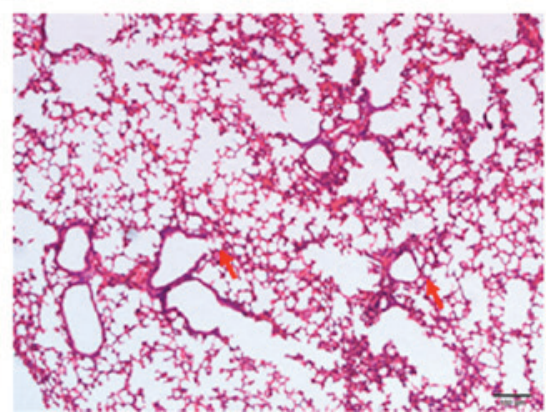

b

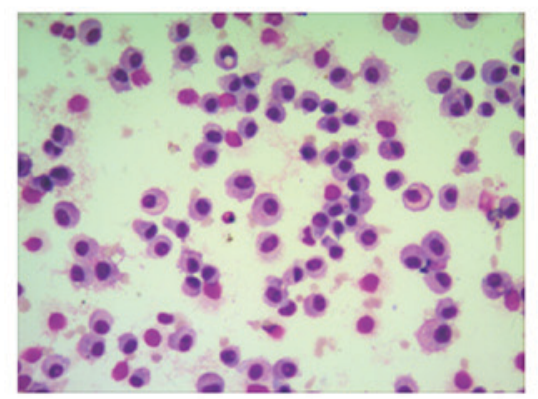

b

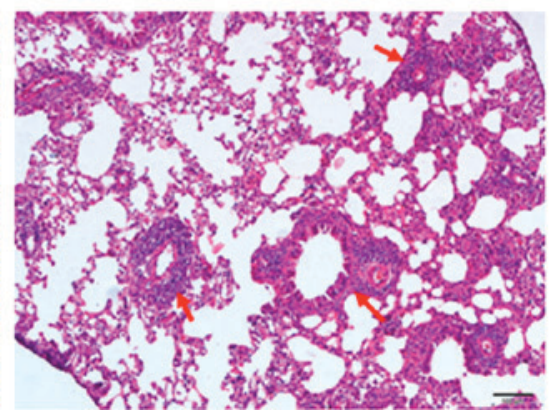

Figure 1. Identification of the murine model of allergic asthma induced by the Derf I protein. (A) 12\% SDS-PAGE analysis of the purified Derf I protein (lane M, protein marker). (B) Airway hyper-responsiveness assay for the mice ("P<0.05 vs. control). (C) Representative images of total inflammatory cells and eosinophils in bronchoalveolar lavage fluid in the $(\mathrm{Ca})$ normal and $(\mathrm{Cb})$ asthma model groups. (D) Formalin-fixed lung sections were stained with hematoxylin and eosin in the (Da) normal and (Db) asthma model groups. Red arrows indicate inflammatory cells (Scale bar, $100 \mu \mathrm{m}$ ). Derf I, Dermatophagoides farinae I.

slight modifications. Briefly, mice were sacrificed by euthanasia, and BALF was obtained using $1 \mathrm{ml}$ PBS containing protease inhibitor cocktail (Roche Applied Science, Mannheim, Germany). Cytospin preparations were prepared and counted using Liu's stain under an optical microscope. Cells were classified as eosinophils according to morphologic and histologic criteria (29).

Measurement of cytokines in BALF and the splenocyte culture medium. The splenocyte cells from the mice were cultured in RPMI-1640 medium with 10\% fetal bovine serum (Thermo Fisher Scientific, Inc., Waltham, MA, USA) in 24-well plates at a density of $5 \times 10^{4} /$ well, stimulated with the recombinant
Derf I protein $(200 \mu \mathrm{g} /$ well $)$, and incubated at $37^{\circ} \mathrm{C}$ for $72 \mathrm{~h}$. The IL-4, IL-10 and INF- $\gamma$ levels in the splenocyte culture medium and BALF were detected using an ELISA kit (catalog no. 421701, Biolegend, Inc.).

Reverse transcription-quantitative polymerase chain reaction (RT-qPCR). RT-qPCR was performed to detect the mRNA expression of ATP5b on an Applied Biosystem 7000 Sequence Detection System (Thermo Fisher Scientific, Inc., Waltham, MA, USA), which was performed as described by Ding et al (28) and Zuo et al (30). Five micrograms of total RNA from each sample was reverse transcribed to cDNA using an A3500 RT system (Promega Corporation, Madison, WI, USA). The following 
Table I. Total cell number and number of eosinophils in bronchoalveolar lavage fluid.

\begin{tabular}{lcc}
\hline Cell $\left(\times 10^{4} / \mathrm{ml}\right)$ & Control group & Model group \\
\hline Total cells & $20.30 \pm 3.35$ & $64.50 \pm 5.08^{\mathrm{a}}$ \\
Eosinophils & 0 & $15.32 \pm 3.04^{\mathrm{a}}$ \\
\hline
\end{tabular}

${ }^{\mathrm{a}} \mathrm{P}<0.05$.

A

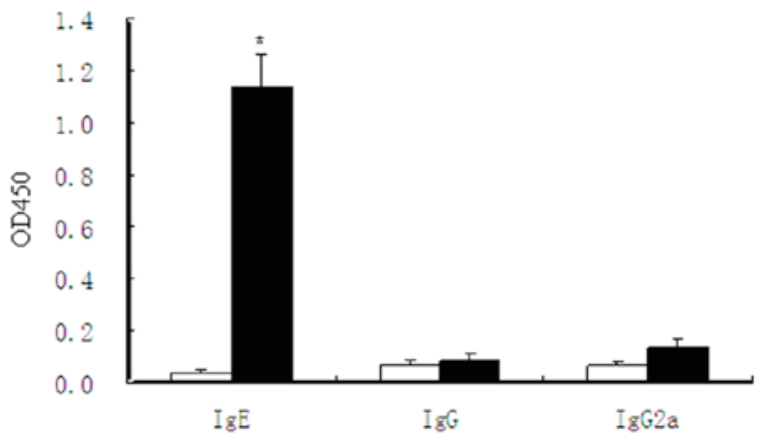

B

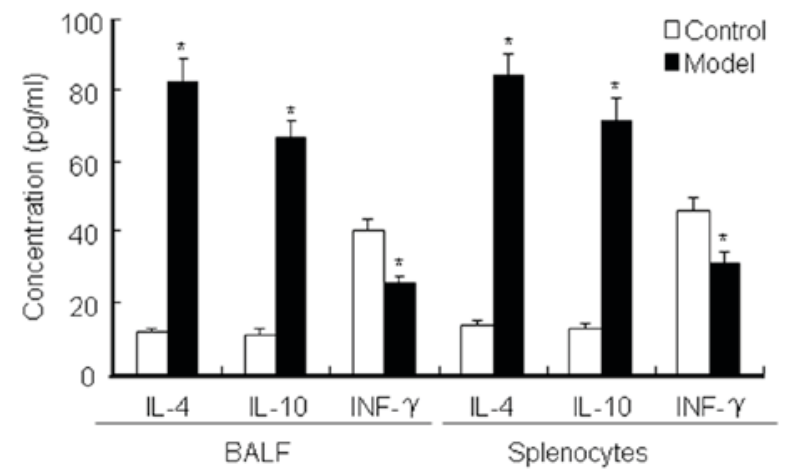

Figure 2. Allergic asthma model group induced with the Dermatophagoides farinaeI protein exhibited an allergen-specific Th2 immune responses. (A) Allergen-specific antibodies in serum. (B) Cytokine production in spleen cell cultures and BALF, ${ }^{*} \mathrm{P}<0.05$ vs. control. OD, optical density; Ig, immunoglobulin; IL, interleukin; INF, interferon; BALF, bronchoalveolar lavage fluid.

forward and reverse primers were used: Forward, AGTTGC TGAGGTCTTCACGG and reverse, CTTTGCCACGGCTTC TTC for ATP5b; and forward, TGGCAGAGATGCGTGGAGA and reverse, GGCAAGTCTTCCGAGTAGTTTT for GAPDH. The PCR conditions were as follows: 5-mindenaturation at $95^{\circ} \mathrm{C}$ followed by $40 \mathrm{cycles}$ at $95^{\circ} \mathrm{C}$ for $30 \mathrm{sec}, 55^{\circ} \mathrm{C}$ for $30 \mathrm{sec}$, and $72^{\circ} \mathrm{C}$ for $30 \mathrm{sec}$. Amplification of the target gene was monitored as a function of increased SYBR-Green. I (Qiagen GmbH, Hilden, Germany) fluorescence. An analysis threshold was set, and the cycle threshold (Cq) was computed for each sample (31). The comparative difference in gene expression was then determined.

RNA interference. siRNA targeting human ATP5b was delivered into ASMCs using the Lipofectamine ${ }^{\circledR} 2000$ reagent (Invitrogen; Thermo Fisher Scientific, Inc.) according to the manufacturer's instructions. In addition, a non-targeting siRNA pool (Dharmacon, Inc., Lafayette, CO, USA) was used at the same concentration as a control for the RNA interference assays. After $48 \mathrm{~h}$ of transfection, cells were subjected to MTT assays or RNA were collected and analyzed by RT-qPCR.

MTT assay. ASMCs were seeded into96-well culture plates at adensity of 500 cells/well with scramble siRNA-ATP5b and siRNA-ATP5b. After $48 \mathrm{~h}$, the cell culture was removed and $20 \mu \mathrm{l}$ of MTT was added to each well. The cells were further cultured at $37^{\circ} \mathrm{C}$ for $4 \mathrm{~h}$, and the cell culture was removed and $150 \mu \mathrm{l}$ DMSO was added to dissolve crystals completely by pipetting up and down. A microplate reader (SynergyH1; Bio-Tek Instruments, Inc., Winooski, VT, USA) measured the corresponding absorption value at a wavelength of $562 \mathrm{~nm}$ indicated cell proliferation as the number of live cells was proportional to the optical density value.

Statistical analysis. The data are expressed as the mean \pm standard deviation. Student's t-test was used for the statistical analysis of interval data and $\mathrm{P}<0.05$ was considered to indicate a statistically significant difference.

\section{Results}

Identification of the murine model of allergic asthma induced by DerfI. In the current study, DerfI as an important antigen of asthma was applied to construct the asthma model. Purified DerfIprotein was obtained (Fig. 1A). AHR changes were assessed by methacholine challenge $24 \mathrm{~h}$ after the final allergen challenge. The results (Fig. 1B) demonstrated that AHR in the model groups was significantly greater $(\mathrm{P}<0.05)$ than in the normal control group. In addition, the AHR of the mice increased with the increasing concentration of methacholine. Fig. $1 \mathrm{C}$ and Table I showed that the total counts of cells and inflammatory cells in the BALF sampled from the model groups were significantly greater than those in the normal group $(\mathrm{P}<0.05)$, particularly the eosinophils. As shown in Fig. 1D, lung tissue samples from the model group were damaged by internal hemorrhage and edema. The bronchial and vascular walls became thickened and infiltrated by a marked number of inflammatory cells. In addition, the trachea in the models was filled with markedly more mucus than the normal control group. However, lung tissue structures in the normal group were well defined without discernible damage or edema, and the trachea and blood vessels were not infiltrated peripherally by inflammatory cells. Thus, the asthma model had been successfully induced.

Allergen-specific T helper (Th)2 immune responses induced by the DerfI protein. Serum IgE, IgG and IgG2a levels were measured by ELISA to evaluate the asthma model. The results (Fig. 2A) showed that the levels of serum IgEin the asthma model group were significantly higher than those in the normal control group $(\mathrm{P}<0.05)$. Furthermore, the concentrations of IL-4, IL-10 and IFN- $\gamma$ in the splenocyte culture medium supernatant and BALF were detected by ELISA. The asthma model groups (Fig. 2B) exhibited allergen-specific Th2 immune responses, where by IL-4 and IL-10 levels were evidently upregulated compared with the normal control group $(\mathrm{P}<0.05)$. However, the IFN- $\gamma$ level in the asthma model 
Table II. Analysis of mass spectral data.

\begin{tabular}{|c|c|c|c|c|c|}
\hline Spots & Master no. & Score & NCBInr no. & Protein name & Expression \\
\hline 1 & 701 & 382 & gil7331218 & TPA exp: keratin Kb40 & - \\
\hline 2 & 1103 & 240 & gil13775198 & SH3 domain-binding glutamic acid-rich-like protein 3 & + \\
\hline 3 & 2304 & 269 & gil55291 & Alpha-tubulin isotype M-alpha-2 & + \\
\hline 4 & 2602 & 612 & gil26344461 & Unnamed protein product & + \\
\hline 5 & 2606 & 1106 & gil23272966 & Atp5b protein & + \\
\hline 6 & 3302 & 500 & gil6678281 & Indolethylamine N-methyltransferase & - \\
\hline 7 & 3401 & 391 & gil2437840 & Annexin III & - \\
\hline 8 & 3604 & 646 & gil22164798 & Selenium-binding liver protein & + \\
\hline 9 & 3701 & 306 & gil191765 & Alpha-fetoprotein, partial & - \\
\hline 10 & 3702 & 711 & gil26340966 & Alpha-fetoprotein, partial & + \\
\hline 11 & 3803 & 94 & gil26080429 & Aldehyde dehydrogenase family 16 member A1 & - \\
\hline 12 & 4605 & 459 & gil468546 & CCT (chaperonin containing TCP-1) beta subunit & - \\
\hline 13 & 4805 & 643 & gil199765 & Moesin & - \\
\hline 14 & 5307 & 135 & gil7242156 & Acyl-protein thioesterase 2 & + \\
\hline 15 & 6304 & 163 & gil54855 & Triosephosphate isomerase & - \\
\hline 16 & 6307 & 167 & gil6680121 & Glutathione S-transferase Mu 2 & + \\
\hline 17 & 6405 & 274 & gil293317 & Adenylyl cyclase-associated protein & + \\
\hline 18 & 6702 & 590 & gil62653546 & Glyceraldehyde-3-phosphate dehydrogenase-like & + \\
\hline 19 & 6703 & 859 & gil6678359 & Transketolase & + \\
\hline 20 & 8303 & 125 & gil424143 & Heat shock protein HSP27 & - \\
\hline 21 & 8403 & 569 & gil62653546 & Glyceraldehyde-3-phosphate Dehydrogenase & + \\
\hline 22 & 8408 & 186 & gil1125026 & 3-hydroxyacyl CoA dehydrogenase & + \\
\hline 23 & 9301 & 507 & gil6671688 & Carbonyl reductase [NADPH] 2 & + \\
\hline
\end{tabular}

Table III. Mascot scores of representative ATP5b protein matched peptides.

\begin{tabular}{rlllll}
\hline 1 & MLSLVGRVAS & ASASGALRGL & SPSAALPQAQ & LLLRAAPAGV & HPARDYAAQA \\
51 & SAAPKAGTAT & GRIVAVIGAV & VDVQFDEGLP & PILNALEVQG & RDSRLVLEVA \\
101 & QHLGESTVRT & IAMDGTEGLV & RGQKVLDSGA & PIKIPVGPET & LGRIMNVIGE \\
151 & PIDERGPIKT & KQFAPIHAEA & PEFIEMSVEQ & EILVTGIKVV & DLLAPYAKGG \\
201 & KIGLFGGAGV & GKTVLIMELI & NNVAKAHGGY & SVFAGVGERT & REGNDLYHEM \\
251 & IESGVINLKD & ATSKVALVYG & QMNEPPGARA & RVALTGLTVA & EYFRDQEGQD \\
301 & VLLFIDNIFR & FTQAGSEVSA & LLGRIPSAVG & YQPTLATDMG & TMQERITTTK \\
351 & KGSITSVQAI & YVPADDLTDP & APATTFAHLD & ATTVLSRAIA & ELGIYPAVDP \\
401 & LDSTSRIMDP & NIVGNEHYDV & ARGVQKILQD & YKSLQDIIAI & LGMDELSEED \\
451 & KLTVSRARKI & QRFLSQPFQV & AEVFTGHMGK & LVPLKETIKG & FQQILAGEYD \\
501 & HLPEQAFYMV & GPIEEAVAKA & DKLAEEHGS & & \\
\hline
\end{tabular}

Matched peptides presented in bold. The peptide sequences obtained by mass spectrometry analysis were compared with the representative ATT5b.

group was significantly lower than that in the normal control group $(\mathrm{P}<0.05)$, which enhances inflammatory and immunosuppressive function. These data demonstrated that Derf I protein disturbed the Th1/Th2 balance, which promoted the Th2 immune response and suppressed the Th1 response.

Mass spectral analysis and identification of ATP5b. A total of 23 monoisotopic peaks were input into the Mascot search engine to search the Swiss-Prot database (http://www.gpmaw. com/html/swiss-prot.html). The annotation of all the identified proteins is summarized in Table II. The query result showed that protein spot 2606 is the ATP5b protein. In addition, the database query result and mascot score of a representative ATP5b protein are demonstrated in Table III and Fig. 3.

ATP5b was identified as an overexpressed protein and is involved in cell proliferation. It was further verified by RT-qPCR that ATP5b was expressed in the asthma model 


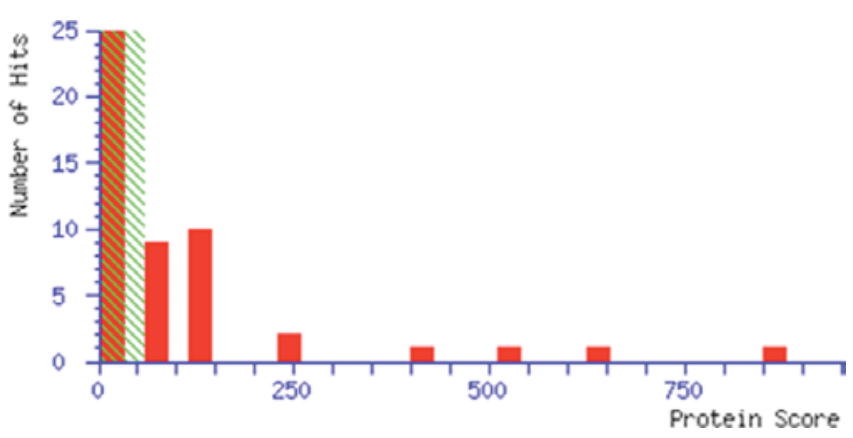

Figure 3. Mass spectral analysis of protein spot 2606. Database query result and score of protein spot 2606. Mascot Score Histogram. Ions score is $-10 * \log (\mathrm{P})$, where $\mathrm{P}$ is the probability that the observed match is a random event. Individual ions scores $>58$ indicate identity or extensive homology $(\mathrm{P}<0.05)$. Protein scores are derived from ions scores as a non-probabilistic basis for ranking protein hits.
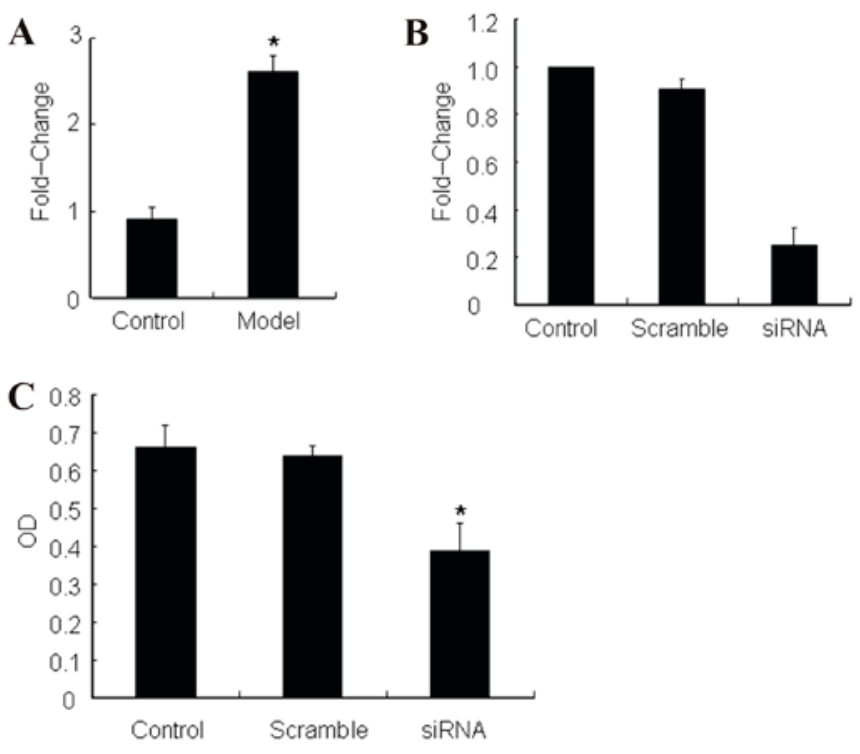

Figure 4. Overexpression of ATP5b protein was observed and ATP5b silencing decreased cell proliferation. (A) ATP5b was verified to be highly expressed in the asthma model using reverse transcription-quantitative polymerase chain reaction ("P<0.05 vs control). (B) ATP5b was knocked down in ASMCs. (C) Silencing of ATP5b decreased cell proliferation of ASMCs ( $\mathrm{P}<0.05$ vs. control). ATP5b, ATP synthase, $\mathrm{H}^{+}$transporting, mitochondrial F1 complex, $\beta$ polypeptide; OD, optical density.

mice to a significantly greater extent when compared with the normal control mice (Fig. 4A). In order to confirm the role and function of ATP5b, the experiments were designed to silence ATP5b expressionin ASMCs and detect its effect on cell proliferation (Fig. 4B). The data indicated that silencing of ATP5b inhibited ASMC growth by MTT (Fig. 4C). Thus, overexpression of ATP5b enhances ASMC proliferation.

\section{Discussion}

Asthma is an inflammatory disease of the airways. Sensitivity to asthma is determined by many factors, such as multigenic predisposition, aberrant immune response and environmental factors (32).

More than $50 \%$ of asthma cases are caused by allergies to environmental allergens (33). Clinicians may effectively intervene in these factors to prevent the development of asthma (34). One of the most frequent allergens associated with asthma is dust mite, as $10 \%$ of individuals with asthma are allergic to it (35). Therefore, dust mite is often used to induce experimental asthma in mice models that closely resemble human asthma $(36,37)$. Therefore, in the current study, Derf I was selected as the important dust mite antigen to construct the asthma model.

In the present study, the recombinant protein, Derf I was used to create the asthma model. The results demonstrate that construction of the animal model was successful, as the typical symptoms, including persistent inflammation, hyper-reactivity and remodeling of the airways (involving smooth muscle thickening, mucus overproduction and sub epithelial thickening) were observed. There are certain characteristics of airway inflammation in asthma resulting from bronchial wall infiltration due to eosinophils, T lymphocytes and activated mast cells. The current data show that the model groups had specific Th2 immune responses, where IL-4 and IL-10 levels were evidently upregulated compared with the normal control group $(\mathrm{P}<0.05)$. However, the IFN- $\gamma$ level in the model mice was significantly lower than that of the control mice $(\mathrm{P}<0.05)$. The above data indicated that the DerfI protein promoted the Th2 immune response and suppressed the Th1 response. Our results are consistent with those of Mihaltan reports that cytokines from Th2 cells are key in mediating airway inflammation (38).

In the current study, ATP5b was observed to be overexpressed in the asthma model. Recent studies show that ATP5b is a subunit of a mitochondrial ATP synthase complex (39). ATP5b, as a receptor for various ligands, is involved in biological processes, such as metabolism of lipid formation, regulation of proliferation, differentiation and recognition of immune responses of tumor cells $(39,40)$. The present study indicated that ATP5b overexpression leads to ASMC proliferation, since rapidly proliferating cells have a high demand for energy and glycolytic intermediates for anabolic processes. Furthermore, certain glycolytic enzymes directly participate in pathways of proliferation as ATP5b increases ATP extracellularly. However, when the ATP5b was knocked down in ASMCs, decreased cell growth was observed. The present results are consistent with the study by Huang et al (40), which reports that targeting breast cancer cell lines with ATP5b inhibitor, aurovertin B decreases proliferation $(40,41)$.

In the present study. The results of proteomics and RT-qPCR demonstrated that, compared with normal control lung tissue samples, the lung tissue samples of the asthma mouse models overexpressed ATP5b, leading to ASMC proliferation and ultimately to ASM thickening. Thus, to the best of our knowledge, this is the first study to report that ATP5b overexpression promoted the proliferation of ASMCs and contributed to airway remodeling.

\section{Acknowledgements}

The present study was supported by the National Nature Science Foundation of China (grant no. 81272960), the Key Research Program from the Science and Technology Department of Hunan Province, China (grant no. 2013WK2010), the Key Research Program from Ministry of Human Resources and Social Security of the People's Republic of China (grant no. 2016-176), Hunan Province Key Laboratory of Tumor 
Cellular and Molecular Pathology (grant no. 2016TP1015) and the Construction Program of the Key Discipline in Hunan Province, China (Basic Medicine Sciences in University of South China).

\section{References}

1. Kokotajlo S, Degnan L, Meyers R, Siu A and Robinson C: Use of intravenous magnesium sulfate for the treatment of an acute asthma exacerbation in pediatric patients. J Pediatr Pharmacol Ther 19: 91-97, 2014.

2. Huang $\mathrm{F}$, Zhang $\mathrm{H}$, Wu M, Yang H, Kudo M, Peters CJ, Woodruff PG, Solberg OD, Donne ML, Huang X, et al: Calcium-activated chloride channel TMEM16A modulates mucin secretion and airway smooth muscle contraction. Proc Natl Acad Sci USA 109: 16354-16359, 2012.

3. Kanchongkittiphon W, Gaffin JM and Phipatanakul W: The indoor environment and inner-city childhood asthma. Asian Pac J Allergy Immunol 32: 103-110, 2014

4. Hon KL, Leung TF and Leung AK: Clinical effectiveness and safety of montelukast in asthma. What are the conclusions from clinical trials and meta-analyses? Drug Des Devel Ther 8 : 839-850, 2014

5. Cannon E: Aligning patient care and asthma treatment guidelines. Am J Manag Care 11 (14 Suppl): S416-S421; quiz S427-S433, 2005

6. Strina A, Barreto ML, Cooper PJ and Rodrigues LC: Risk factors for non-atopic asthma/wheeze in children and adolescents: A systematic review. Emerg Themes Epidemiol 11: 5, 2014.

7. Masoli M, Fabian D, Holt S and Beasley R; Global Initiative for Asthma (GINA) Program: The global burden of asthma: Executive summary of the GINA Dissemination Committee report. Allergy 59: 469-478, 2004.

8. Simpson EL: Atopic dermatitis: A review of topical treatment options. Curr Med Res Opin 26: 633-640, 2010.

9. Shaw TE, Currie GP, Koudelka CW and Simpson EL: Eczema prevalence in the United States: Data from the 2003 National Survey of Children's Health. J Invest Dermatol 131: 67-73, 2011.

10. Van Der Velden J, Sum G, Barker D, Koumoundouros E, Barcham G, Wulff H, Castle N, Bradding P and Snibson K: $\mathrm{K}(\mathrm{Ca}) 3.1$ channel-blockade attenuates airway pathophysiology in a sheep model of chronic asthma. PLoS One 8: e66886, 2013.

11. Li F, Zhou Y, Li S, Jiang F, Jin X, Yan C, Tian Y, Zhang Y, Tong S and Shen X: Prevalence and risk factors of childhood allergic diseases in eight metropolitan cities in China: A multicenter study. BMC Public Health 11: 437, 2011.

12. Redhu NS, Shan L, Al-Subait D, Ashdown HL, Movassagh H, Lamkhioued B and Gounni AS: IgE induces proliferation in human airway smooth muscle cells: Role of MAPK and STAT3 pathways. Allergy Asthma Clin Immunol 9: 41, 2013.

13. Brannan JD and Lougheed MD: Airway hyperresponsiveness in asthma: Mechanisms, clinical significance, and treatment. Front Physiol 3: 460, 2012.

14. Holgate ST: The airway epithelium is central to the pathogenesis of asthma. Allergol Int 57: 1-10, 2008.

15. Knight DA and Holgate ST: The airway epithelium: Structural and functional properties in health and disease. Respirology 8: 432-446, 2003

16. Gregory LG, Mathie SA, Walker SA, Pegorier S, Jones CP and Lloyd CM: Overexpression of Smad2 drives house dust mite-mediated airway remodeling and airway hyper-responsiveness via activin and IL-25. Am J Respir Crit Care Med 182: 143-154, 2010

17. Yamagata S, Tomita K, Sato R, Niwa A, Higashino H and Tohda Y: Interleukin-18-deficient mice exhibit diminished chronic inflammation and airway remodelling in ovalbumin-induced asthma model. Clin Exp Immunol 154: 295-304, 2008.

18. Gabehart KE, Royce SG, Maselli DJ, Miyasato SK, Davis EC, Tang ML and Le Saux CJ: Airway hyperresponsiveness is associated with airway remodeling but not inflammation in aging Cav1-/- mice. Respir Res 14: 110, 2013.

19. Zuo J, Wen M, Lei M, Xiao X and Liu Z: PLGA-Der p1 vaccine inhibited tumor growth in a murine model of lung cancer. Arch Med Res: Dec 16, 2015 (Epub ahead of print).

20. Duramad P, Tager IB, Leikauf J, Eskenazi B and Holland NT: Experession of Th1/Th2 cytokines in human blood after in vitro treatment with chlorpyrifos, and its metabolites, in combination with endotoxin lps and allergen derpl. J Appl Toxicol 26 458-465, 2006.
21. Rachmiel M, Bloch O, Bistrizer T, Weintrob N, Ofan R, Koren-Morag N and Rapoport MJ: Th1/Th2 cytokine balance in patients with both type 1 diabetes mellitus and asthma. Cytokine 34: 170-176, 2006.

22. Placeres-Uray FA, Febres-Aldana CA, Fernandez-Ruiz R, Gonzalez de Alfonzo R, Lippo de Becemberg IA and Alfonzo MJ: M2 Muscarinic acetylcholine receptor modulates rat airway smooth muscle cell proliferation. World Allergy Organ J 6: 22 , 2013.

23. Yan L, Xiao-Ling S, Zheng-Yan C, Guo-Ping L, Sen Z and Zhuang C: HSP70/CD80 DNA vaccine inhibits airway remodeling by regulating the transcription factors T-bet and GATA-3 in a murine model of chronic asthma. Arch Med Sci 9: 906-915, 2013.

24. Wei Y, Xu YD, Yin LM, Wang Y, Ran J, Liu Q, Ma ZF, Liu YY and Yang YQ: Recombinant rat CC10 protein inhibits PDGF-induced airway smooth muscle cells proliferation and migration. Biomed Res Int 2013: 690937, 2013

25. Xiao X, Zeng X, Zhang X, Ma L, Liu X, Yu H, Mei L and Liu Z: Effects of Caryota mitis profilin-loaded PLGA nanoparticles in a murine model of allergic asthma. Int $\mathbf{J}$ Nanomedicine 8 : 4553-4562, 2013

26. Cheng AL, Huang WG, Chen ZC, Peng F, Zhang PF, Li MY, Li F, $\mathrm{Li} \mathrm{JL}, \mathrm{Li} \mathrm{C}, \mathrm{Yi} \mathrm{H}$, et al: Identification of novel nasopharyngeal carcinoma biomarkers by laser capture microdissection and proteomic analysis. Clin Cancer Res 14: 435-445, 2008

27. Li S, Li J, Hu T, Zhang C, Lv X, He S, Yan H, Tan Y, Wen M, Lei $\mathrm{M}$ and Zuo J: Bcl-2 overexpression contributes to laryngeal carcinoma cell survival by forming a complex with Hsp90 $\beta$. Oncol Rep 37: 849-856, 2017.

28. Ding D, Enriquez-Algeciras M, Dave KR, Perez-Pinzon M and Bhattacharya SK: The role of deimination in ATP5b mRNA transport in a transgenic mouse model of multiple sclerosis. EMBO Rep 13: 230-236, 2012

29. Metso T, Venge P, Haahtela T, Peterson CG and Sevéus L: Cell Specific markers for eosinophils and neutrophils in sputum and bronchoalveolar lavage fluid of patients with respiratory conditions and healthysubjects. Thorax 57: 449-451, 2002.

30. Zuo JH, Zhu W, Li MY, Li XH, Yi H, Zeng GQ, Wan XX, He QY, Li JH, Qu JQ, et al: Activation of EGFR promotes squamous carcinoma SCC10A cell migration and invasion via inducing EMT-like phenotype change and MMP-9-mediated degradation of E-cadherin. J Cell Biochem 112: 2508-2517, 2011

31. Livak KJ and Schmittgen TD: Analysis of relative gene expression data using real-time quantitative PCR and the 2(-Delta Delta C(T)) method. Methods 25: 402-408, 2001.

32. Liu MC, Hubbard WC, Proud D, Stealey BA, Galli SJ, Kagey-Sobotka A, Bleecker ER and Lichtenstein LM: Immediate and late inflammatory responses to ragweed antigen challenge of the peripheral airways in allergic casthmatics. Cellular, mediator, and permeability changes. Am Rev Respir Dis 144: 51-58, 1991.

33. Zhao G, Lin X, Zhou M and Zhao J: Association between CC10 $+38 \mathrm{~A} / \mathrm{G}$ polymorphism and asthma risk: A meta-analysis. Pak J Med Sci 29: 1439-1443, 2013.

34. Inoue $\mathrm{Y}$ and Shimojo N: Epidemiology of virus-induced wheezing/asthma in children. Front Microbiol 4: 391, 2013.

35. Bessot JC and Pauli G: Mite allergens: An overview. Eur Ann Allergy Clin Immunol 43: 141-156, 2011.

36. Yao X, Dai C, Fredriksson K, Dagur PK, McCoy JP, Qu X, Yu ZX, Keeran KJ, Zywicke GJ, Amar MJ, et al: 5A, an apolipoprotein A-I mimetic peptide, attenuates the induction of house dust mite-induced asthma. J Immunol 186: 576-583, 2011.

37. Yao X, Fredriksson K, Yu ZX, Xu X, Raghavachari N, Keeran KJ, Zywicke GJ, Kwak M, Amar MJ, Remaley AT and Levine SJ: Apolipoprotein E negatively regulates house dust mite-induced asthma via a low-density lipoprotein receptor-mediated pathway. Am J Respir Crit Care Med 182: 1228-1238, 2010.

38. Mihălțan F and Ulmeanu R: Tiotropium in asthma-a new opportunity? Pneumologia 63: 200-202, 2014 (In Romanian).

39. García J: The calcium channel $\alpha 2 / \delta 1$ subunit interacts with ATP5b in the plasma membrane of developing muscle cells. Am J Physiol Cell Physiol 301: C44-C52, 2011.

40. Huang TC, Chang HY, Hsu CH, Kuo WH, Chang KJ and Juan HF: Targeting therapy for breast carcinoma by ATP synthase inhibitor aurovertin B. J Proteome Res 7: 1433-1444, 2008.

41. Hjerpe E, Egyhazi Brage S, Carlson J, Frostvik Stolt M, Schedvins K, Johansson H, Shoshan M and Avall-Lundqvist E: Metabolic markers GAPDH, PKM2, ATP5B and BEC-index in advanced serous ovarian cancer. BMC Clin Pathol 13: 30, 2013. 